\title{
EL ETERNO RETORNO DE LO MISMO EN EL NIETZSCHE DE HEIDEGGER
}

The Eternal Return of the Same in Heidegger's Nietzsche

\author{
Andrea Díaz Genis
}

Universidad de la República, Uruguay

\begin{abstract}
RESUMEN: Este artículo propone hacer una lectura de la interpretación que Heidegger hace de la idea del eterno retorno en Nietzsche, en tanto pregunta conductora del problema metafísico fundamental acerca de qué es el ser. Trataremos de mostrar cómo Heidegger se explica a través de Nietzsche, y el lugar central que le da a este pensamiento en la filosofía occidental. Eterno retorno y voluntad de poder, aparecen como las dos caras de la misma moneda. Heidegger, de alguna manera «sustancializa» al mostrarnos a un Nietzsche metafísico, cuando, de lo que se trata, para nosotros, es de relativizarlo. La idea del eterno retorno es una idea ética, una idea que nos ayuda, como «perspectiva», a probar el valor de la existencia. Hay que actuar «como si» la vida se volviese a repetir, lo que no significa que deba entenderse como una afirmación ontológica acerca del ser, ni del tiempo.

Palabras clave: eterno retorno - voluntad de poder - existencia - ontología
\end{abstract}

ABSTRACT: This article aims to make a reading of Heidegger's interpretation of the idea of eternal return in Nietzsche, as leading question of fundamental metaphysical problem about what being is. We try to show how Heidegger explains himself through Nietzsche, and the central place given to this thought in Western philosophy. The eternal recurrence and the will to power appear as two sides of the same coin. Heidegger «substantializes» by showing a metaphysical Nietzsche instead of relativizing him, as we need. This article considers the idea of eternal return as an ethical idea, an idea that helps, as a "perspective», to prove the value of life. We must act «as if» life will repeat itself, which does not mean it should be understood as an ontological statement about being or time.

Keywords: Eternal Return - Will to Power - Ontology

\section{EL ETERNO RETORNO EN HEIDEGGER}

Vamos a destacar ciertos aspectos de la propuesta heideggeriana del eterno retorno en Nietzsche que, para nosotros, requieren especial atención (haciendo referencias esporádicas a otros comentaristas). No podemos profundizar aquí en esta propuesta, pero, sin embargo, podemos mostrar ciertos aspectos que nos van a permitir aclarar o profundizar la nuestra. Sólo la idea del eterno retorno de Nietzsche en Heidegger requeriría una o varias tesis, y supondría, entre otras cosas, retomar la filosofía del mismo Heidegger.

Lo primero que destacar es que, para Heidegger, el eterno retorno es el pensamiento fundamental de la metafísica de Nietzsche ${ }^{1}$. Es un pensamiento que de

1. Cf. M. Heidegger, Nietzsche, 2 vols., trad. de J. L. Vermal, Barcelona: Destino, 2000. 
alguna manera retoma la gran pregunta de la filosofía acerca de qué es el $\operatorname{ser}^{2}$, y la responde a manera de síntesis recogiendo las ideas fundamentales acerca del ser y el devenir de la filosofía occidental. Es más, lo que es profundamente interesante para Heidegger es que, para responder a la pregunta por el ser, Nietzsche se retrotraiga a los albores de la filosofía occidental, es decir, a la filosofía griega, y que de alguna manera, por ello, haga un movimiento en círculo que cierra la problemática, al volver al inicio, no permitiendo así su posterior desarrollo.

Esta doctrina planteada por Nietzsche contiene, según Heidegger, un enunciado sobre el ente en su totalidad. En ningún momento Nietzsche habla con estas palabras. Esto por supuesto forma parte de la lectura-interpretación heideggeriana, que es consciente precisamente de su punto de vista hermenéutico. Y hay que destacar este punto: Heidegger hace explícito en todo momento que su lectura es desde un ángulo filosófico, que necesariamente "proyecta», al modo de decir de Gadamer, sus propias obsesiones filosóficas en la lectura que hace del mismo. Aquí hay un elemento interesante que destacar, como dice Savater ${ }^{3}$ : «Nietzsche no es tanto un autor que se explica como un pensador ante el que uno se explica». De alguna manera, Heidegger se explica a través de Nietzsche. Cuando habla del «ente en su totalidad», está hablando desde una terminología que es central en sus propios planteamientos. Heidegger usa esa expresión para nombrar todo lo que no es simplemente nada: la naturaleza, la historia y sus protagonistas, los dioses, e incluso la nada. Pertenece ésta al ente en su totalidad; si no, no habría nada ninguna. También llama ente a lo falso, con el argumento de que, si no fuera ente, no podría engañar. Para Heidegger, aquello por lo que se pregunta, lo digno de ser preguntado, es el ente en su totalidad. A la pregunta le sigue la respuesta dada por Nietzsche con el eterno retorno de lo mismo, que lo coloca en el centro de la metafísica occidental. Se acerca por ello a doctrinas que han contribuido a formar Occidente: el platonismo y el cristianismo. Estas doctrinas, para Heidegger, están tan internalizadas que ya son hábitos de pensamiento. Esto es importante, la doctrina del eterno retorno no tiene una aparición espontánea, sino que surge de la más dura controversia con este pensamiento, sus consecuencias y transformaciones en la época moderna. Esto es muy interesante, pues significa que no podríamos entender la doctrina del eterno retorno si no comprendiéramos al mismo tiempo también esta controversia. El platonismo-cristianismo, vinculados intrínsecamente para Nietzsche, son, por otra parte, los rasgos principales del pensamiento en general y de su historia, tal como lo conocemos en Occidente.

Heidegger entiende que, a través de un proyecto como éste, todas las cosas, la filosofía de Nietzsche, su propia vida, o la vida de quien piense este pensamiento, cambian su semblante y su peso. Es interesante ver este pensamiento también desde el hombre Nietzsche, cuya biografía puede ser entendida, según dice Lou Andreas-Salomét, como «una biografía del sufrimiento». Un hombre que es capaz de pedir, a pesar de su historia, "que se repita», es un hombre poderoso, que es capaz de afirmar la vida a pesar de todos sus males. Creemos que Lou Andreas Salomé no entiende a Nietzsche cuando dice:

2. Sería interesante volver sobre la propuesta heideggeriana de que las tres formulaciones publicadas del eterno retorno (en FW, Za, JGB) son preguntas más que respuestas.

3. F. Savater, Nietzsche, México: UNAM, 1993.

4. Cf. L. Andreas-Salomé, Nietzsche, México: Casa Juan Pablos, 2000. 
Convertirse en el revelador de una doctrina que sólo es soportable si hay de por medio un amor preponderante por la existencia, que sólo podría actuar de manera exaltadora en la medida en que el hombre encontrara en ella su posibilidad de elevación hasta divinizar la vida, en verdad debió ser un terrible contrasentido con su sentir más íntimo, contradicción que terminó por destruirlo ${ }^{5}$.

El pensamiento del eterno retorno es, realmente, el pensamiento más extremo, más abismal. En un pensador como él, profundamente involucrado con lo que piensa — diríamos, vitalmente involucrado- y teniendo en cuenta esta «biografía del sufrimiento» que constituye su vida, lo más lógico es pensar que un pensamiento tal lo destruyera. Esto no ocurre si este pensamiento es entendido como posibilidad; desde este ángulo se transforma en un pensamiento vitalizador, constructivo ${ }^{6}$. En La gaya ciencia se muestra este pensamiento como posibilidad, no como hecho («no existen hechos, sólo interpretaciones» dice en sus escritos póstumos). Y es precisamente en cuanto posibilidad como adquiere su fuerza transformadora. Como bien apunta Heidegger, el eterno retorno es un "grave peso" (así lo califica Nietzsche en FW) y, como tal, es la "suprema fórmula de afirmación de la vida». La vida, en definitiva, tiene «valor» por sí misma, no necesita de algo trascendente que la justifique, ni debe ser negada porque no cumpla con no sé qué objetivos trascendentes. El fin y la meta es la vida misma.

En Zaratustra, Heidegger interpreta la necesidad de Nietzsche de encontrar a aquel hombre, que es precisamente el «superhombre», capaz de soportar la idea del eterno retorno; de encontrar al hombre que sea capaz de no quebrantarse ante esa idea. El «enano», personaje, o alter ego que aparece en Zaratustra, no puede precisamente superar lo feo y horrible del anillo eterno. Si todo retorna, todo lo que queda hacia adelante es indiferente. Zaratustra reconoce la necesidad de que regrese tanto lo pequeño como lo grande. Como dice Klossowski:

[...] para que esta revelación tenga un sentido, sería necesario que yo perdiera la conciencia de mí mismo, y que el movimiento circular del retorno se confundiera con mi inconsciencia hasta que el movimiento me hubiera devuelto al instante en que se me reveló la necesidad de recorrer toda la serie de mis posibilidades?

Es decir, antes de llegar a esta «tonalidad del alma» que Klossowski llama Stimmung, donde me es revelada la idea del eterno retorno, y por ello olvidada, tuvo que transcurrir todo un círculo de acontecimientos, posibilidades realizadas, todas las experiencias vivibles, no sólo mis experiencias, sino de todo el universo que me rodea, para llegar a este estado actual, todo lo pequeño y lo grande, todos los sufrimientos y alegrías, etc. Se trata de volver a querer todas las experiencias, todas las alegrías y sufrimientos, pues para llegar a este momento en que digo, repito y hago consciente el eterno retorno, necesito de todas las experiencias que me preceden. Zaratustra es precisamente el sabio capaz de

5. Klossowski cita a Salomé, «Olvido y anámnesis en la experiencia vivida del eterno retorno de lo mismo", cf. Casa del Tiempo, México: Universidad Autónoma Metropolitana, 1989, p. 101.

6. Así y todo, aunque no pensemos el eterno retorno como posibilidad sino como hecho (aunque no creemos que ésta fuera una interpretación correcta), el peso está en la afirmación de la vida, en la voluntad de poder decir «sí», incluso a lo terrible.

7. Ibid, p. 3 
percibir que lo grande y lo pequeño se pertenecen mutuamente, y todo se hace necesario para llegar al momento en el que estoy, para ser yo mismo, y afirmarme en mi mismidad con todas mis circunstancias.

Hay una importancia del instante en la idea del retorno: el instante como el choque entre lo pasado y lo futuro. Es interesante que aquí, a diferencia de la postura mítica del eterno retorno, estudiada por nosotros a través de Eliade, el hincapié no está puesto en lo eterno ${ }^{8}$, sino en la importancia de lo breve y lo pasajero. No dejar pasar sin valor el aquí y ahora, el instante, pues se va a volver a repetir eternamente. En cuanto a la tercera comunicación del eterno retorno que aparece en Más allá del bien y del mal, Heidegger resalta cómo la idea del eterno retorno nos abre al ideal inverso de la «negación de la vida» schopenhaueriana. Nos abre a la idea de un hombre desbordante de vida y alegría, que es capaz de decir da capo no sólo a la pieza sino a todo el espectáculo. Para Heidegger habría que diferenciar la idea del eterno retorno que Nietzsche tuvo la intención explícita de mostrar $^{9}$ de las notas inéditas. Hay una gran desproporción, en el pensamiento Nietzscheano, entre lo publicado acerca del eterno retorno y lo pensado y lo sabido. Desde el período de 1881, que es cuando aparece la idea, hasta el final de su vida lúcida en 1889, Nietzsche se refiere constantemente al eterno retorno, por ser precisamente una de las ideas centrales de su pensamiento. La misma doctrina de la voluntad de poder es, según Heidegger, deudora de la idea del eterno retorno. Sus escritos póstumos, recogidos con el nombre de "La voluntad de poder", en realidad habían sido en principio pensados por Nietzsche bajo el título de «Filosofía del eterno retorno». La voluntad de poder surge - no le cabe duda a Heidegger- desde el eterno retorno, «como el río a la fuente» ${ }^{10}$. En cuanto a las llamadas «demostraciones científicas» del eterno retorno ${ }^{11}$, que aparecen en sus escritos inéditos, no son para nada, según Heidegger, de corte científico sino de corte filosófico, y así deberían ser entendidas. Han sido descartadas como erróneas o como pobres, y por eso no han sido tomadas muy en serio. La «demostración» propuesta por Nietzsche habla de «devenir», «retorno», «igualdad», «espacio», «tiempo», etc. Son referencias al ente en su totalidad, por lo tanto referencias metafísicas y no físicas. Trabajan sobre la intersección de dos «megaideas» que han sido fundamentales para el pensamiento filosófico, las ideas del ser y el tiempo. La ciencia sólo trata de un ámbito específico del ser y, para hablar sobre sí mismo o usar esta terminología que nos presenta Nietzsche, no tiene más remedio que salir de sí misma y hacer filosofía. Otro aspecto interesante que destacar es la aparente contradicción del pensamiento Nietzscheano, que presenta la idea del eterno retorno como «esencia del mundo", pero a la vez es consciente de que habla desde "un ángulo», es decir, que es meramente una interpretación de cómo funcionan el ser y el tiempo, pero no una explicación objetiva del mismo. Estos dos aspectos son irreconciliables para Heidegger, pero

8. Cf. A. Díaz Genis, El eterno retorno de lo mismo o el terror a la historia, Montevideo: Ideas, 2008 .

9. Nos referimos a La gaya ciencia, Así habló Zaratustra y Más allá del bien y del mal.

10. Klossowski dice que Zaratustra quiere un cambio, pero no del mundo, sino de su voluntad, la voluntad de poder consistiría en volver a querer lo consumado no querido, P. Klossowski, op. cit.

11. Klossowski estaría también de acuerdo con Vattimo en desechar las formulaciones científicas del eterno retorno: «Ni la concepción cíclica de la historia corresponde originalmente a Nietzsche, ni sus especulaciones mecanicistas sobre los quanta aportan nada a la experiencia del Retorno» (ibid., p. 119). 
sin embargo ambos están presentes en Nietzsche. No se puede captar la esencia del mundo fuera del ángulo; pero, si se hace desde un ángulo, no es la esencia del mundo. Para Heidegger, precisamente el que todo pensamiento sea punto de vista es un aspecto esencial e inevitable de toda filosofía. O bien concedemos la exclusión de toda humanización y llegamos a algo así como al punto de vista de la falta de punto de vista, o bien reconocemos que la esencia del hombre es hablar desde un «ángulo», y entonces hay que renunciar a la «captación no humanizadora de la totalidad del mundo». Nietzsche no se hizo consciente de esta contradicción y se manejó por ambos caminos - esta postura se diferencia netamente de la postura de Vattimo ${ }^{12}$ sobre el tema; el filósofo italiano se decide a pensar la idea del eterno retorno tan sólo como posibilidad, como interpretación, y descarta toda posibilidad de retomar esta idea como «esencia del mundo»participamos de la idea de pensar el eterno retorno como posibilidad y no como «realidad», en términos griegos, presencia, ousia ${ }^{13}$.

Otra conexión que nos parece interesante, retomada por Heidegger a partir de Nietzsche, es la idea de que el eterno retorno replantea en una forma original el problema también clásico de la filosofía sobre la libertad y el determinismo. El eterno retorno, como pregunta, nos remite a la relación entre libertad y necesidad. A partir de la idea del eterno retorno podemos preguntarnos qué puede significar la libertad si todo se repite, es decir, si todo está predeterminado. Nosotros pensamos que hay que tratar de diferenciar la idea de fatalismo (el fatum) de la idea del eterno retorno. El fatalismo, en sí, es un encadenamiento preestablecido por una predisposición, que se desarrolla y se realiza de una manera irreversible. Cualquier cosa que haga o diga, contrariamente a lo que pienso, obedece a un proyecto que se me escapa o ignoro. El eterno retorno de lo mismo, tal y como lo propone Nietzsche, requiere sin embargo la participación del individuo. Hay un querer que todo se repita, hay una decisión, y no simplemente un padecimiento que nos lleva a querer que todo se repita, a querer lo irreversible una vez más. En esto consiste la voluntad de poder, como ya vimos, y no puede darse, sin esa participación activa y voluntaria, la experiencia del eterno retorno como experiencia del superhombre. El padecimiento, la fatalidad, o ese «rechinar de dientes» se dan precisamente en aquel que es incapaz de participar de esta voluntad, de este querer y por eso «padece» el anillo eterno como una pesadilla. Para Heidegger, habría un acercamiento a las posturas de Heráclito y de Parménides, en la propuesta Nietzscheana del eterno retorno, entendiendo a Heráclito y Parménides tal y como él los entendía. Nietzsche no estaría dispuesto a admitir el eterno fluir, esto sería la inconsistencia total y nos llevaría a la destrucción. El eterno retorno detendría el eterno fluir en favor del ser. Sería una especie de «redención» del eterno fluir. Pero esto no quiere decir eliminar el fluir, pues éste se da dentro del círculo. El devenir es conservado como devenir, pero se introduce la consistencia. El «ente en su totalidad» sigue siendo un río, pero un río que, una vez terminado su ciclo, fluye una y otra vez. Para Heidegger, es central que el pensamiento fundamental de Nietzsche esté fundado nada

12. Cf. G. Vattimo, Introducción a Nietzsche, trad. de J. Binaghi, Barcelona: Península, 1996; El sujeto y la máscara, trad. de J. Binaghi, Barcelona: Península, 1998; Diálogo con Nietzsche. Ensayos 1961-2000, trad. de C. Revilla, Barcelona: Paidós, 2002.

13. Sobre nuestra posición, cf. A. Díaz Genis, op. cit. 
menos que en las dos determinaciones básicas del ente que provienen del inicio de la filosofía occidental: el ser y el devenir. Como ya habíamos mencionado, al volver al inicio, Nietzsche cierra el círculo y no se puede volver a preguntar por la "pregunta conductora». La propuesta heideggeriana hace hincapié en el aspecto metafísico de la doctrina del eterno retorno ${ }^{14}$. Es importante por ello tenerla bien presente, aunque nosotros — como ya hemos señalado, apoyándonos en Vattimo- adoptaremos la postura de que el aspecto fundamental de esta doctrina es el ético. ¿Pero por qué metafísica? ¿Por qué Heidegger hace hincapié en este aspecto?

Primero y antes de nada debemos decir que el fundamento del eterno retorno es, para Heidegger, la voluntad de poder. Esto es así porque sólo a partir de la voluntad de poder, como carácter de fuerza del mundo en su totalidad, puede demostrarse el carácter del eterno retorno: porque el eterno retorno sólo es posible si al ente en su totalidad le corresponde la constitución de la voluntad de poder. La voluntad de poder sería el fundamento real del eterno retorno.

El pensamiento de Nietzsche pretende afrontar toda la filosofía occidental, que es interpretada como platonismo. Si se confronta con toda la filosofía occidental, tendrá que confrontarse con los valores supremos de dicha filosofía. Es decir, tendrá que realizar una transvaloración de todos los valores. Su filosofía será un contramovimiento, y su pensamiento un contrapensamiento, y el eterno retorno, una contracreencia que sostiene y guía todo el movimiento. Pero hay un «estado de cosas» que genera la posibilidad de transvaloración en Nietzsche, y a esto lo llama nihilismo. Orientados por la palabra «nihilismo» tal como proviene de Nietzsche, es una experiencia que trata del nihil, de la nada. La nada es la negación de algo desde el punto de vista formal. Más precisamente, la negación de todo algo. La posición de la nada es la negación del todo en su totalidad. Lo que determina al ente en su totalidad es el ser. Nietzsche mismo comprende su propio pensamiento dentro del nihilismo, es el nihilista "perfecto» en tanto él ya ha vivido hasta el final el nihilismo, lo tiene detrás de sí, por debajo y fuera de sí. El eterno retorno piensa el ente de manera tal que, desde el ente en su totalidad, viene hacia nosotros una apelación constante, la de si queremos simplemente dejarnos llevar o si, por el contrario, queremos ser creadores, es decir, si queremos ser los medios y las condiciones para querer devenir tales ${ }^{15}$. El eterno retorno tiene también un carácter nihilista en la medida en que en él tampoco se piensa una meta última para el ente. En este pensamiento se eterniza el «para nada», la falta de meta última: es el pensamiento paralizador. Pero de este modo el pensamiento Nietzscheano sólo es pensado a medias, no se lo aprehende en su carácter de instante y decisión. Sólo cuando esto ocurre es el momento de la superación para Heidegger. El pensamiento del eterno retorno debe pensarse nihilístamente. Es decir, dicho pensamiento sólo puede pensarse en la medida en que también se piensa el nihilismo como aquello que tiene que

14. Aunque también el aspecto ético es fundamental para Heidegger. El contenido del eterno retorno es metafísica porque se refiere - como ya dijimos- al ente en su totalidad. Pero, puesto que este pensamiento es el pensamiento más grave y, en cuanto tal, determina el ser del hombre, y por lo tanto a nosotros mismos en medio del ente, la verdad de este pensamiento sólo será verdad si es «nuestra verdad".

15. Ibid., p. 352 . 
ser superado y que está superado en la voluntad de crear. «Sólo quien extiende su pensar hasta el más extremo estado de necesidad del nihilismo será capaz de pensar también el pensamiento que lo supera como dando un giro a la necesidad y como necesario» ${ }^{16}$.

Es interesante la forma en que interpreta Heidegger el lenguaje figurado de Zaratustra. En «De la visión y el enigma», la referencia a la niñez es para Heidegger la historia anterior del Zaratustra, el surgimiento y ascenso del nihilismo. Si es medianoche, esto debe interpretarse como el tiempo más alejado del mediodía (es decir, del eterno retorno). "Cuando era niño»: se alude a la época en que Nietzsche estaba influido por Wagner y Schopenhauer. La serpiente negra es el sombrío «siempre igual» del nihilismo, su fundamental carencia de meta y de sentido; es el nihilismo mismo. El nihilismo no se puede sacar de afuera, quitarlo a jirones y empujones, poniendo en lugar del Dios cristiano otro ideal -la razón, el progreso, el socialismo, etc. El pastor, al intentar quitar la serpiente, se aferra más. Todo es en vano, si no es el hombre mismo quien hunde sus dientes en el peligro. El nihilismo sólo es superado cuando se lo agarra por la cabeza, donde está lo que lo determina y lo dirige. El pastor es Zaratustra: se transforma en convaleciente cuando ha pasado por la enfermedad, cuando ha aprendido que $\underline{\text { el }}$ ahogo de la serpiente negra forma parte del saber, que el saber tiene que liquidar necesariamente el hastío que provoca el hombre en medio del nihilismo.

¿Qué es el instante? Es la decisión en la que toda la historia anterior, en cuanto historia del nihilismo, es llevada a la confrontación y al mismo tiempo es superada. El pensamiento del eterno retorno sólo es si es este pensamiento de superación ${ }^{17}$. De un lado, está el «todo es lo mismo», nada merece la pena, y, del otro, todo retorna, cada instante importa. Se trata de que todo es indiferente, o nada es indiferente. Si se toma este pensamiento supuestamente por sí mismo, «todo gira en círculo», quizás no sea más, dice Heidegger, que una construcción de la locura. Y éste no es el pensamiento de Nietzsche y, sobre todo, no es el pensamiento por sí mismo, porque este pensamiento es por sí en cuanto pensamiento de superación y sólo en cuanto tal.

Para Heidegger, es necesario trasladarse al estado de la situación en la que surge como necesario el nihilismo. En este pensamiento lo que hay que pensar, por el modo en que ha de ser pensado, repercute sobre lo que se piensa. En Nietzsche, pensar la eternidad requiere trasladarse al instante. El eterno retorno requiere la confrontación con el «todo es lo mismo», «nada merece la pena»; en definitiva, con el nihilismo. «Sólo se piensa el eterno retorno si se lo piensa de una manera nihilista e instantánea. Pero en un pensar así, el que lo piensa penetra él mismo en el anillo del eterno retorno, aunque de modo tal que contribuye a conquistarlo y a decidirlo» ${ }^{18}$. Heidegger se pregunta algo interesante. El pensamiento más importante de Nietzsche repercute sobre el que lo piensa y lo integra en lo pensado. ¿Por qué? ¿Es esto algo propio de la filosofía Nietzscheana y su concepción del pensamiento, o existe esta relación en toda filosofía en cuanto filosofía? El hecho de que lo pensado repercuta en quien lo piensa se debe, precisamente, a que el eterno retorno piensa al ente en su totalidad, según Heidegger. Y un

16. Ibid., p. 353.

17. Ibid., p. 359

18. Ibid., p. 360 . 
pensamiento de este tipo constituye un pensamiento metafísico. Y aquí contestamos la pregunta que nos habíamos planteado anteriormente. Para Heidegger, la idea del eterno retorno es el pensamiento metafísico de Nietzsche. Y es por eso por lo que su repercusión integra y su integración repercute. El pensamiento del eterno retorno forma parte de lo que Heidegger llama «la posición metafísica fundamental». Primero, esta posición metafísica fundamental pertenece a la historia occidental y contribuye esencialmente a determinarla. Por metafísica Heidegger entiende el dominio de ese preguntar de la filosofía en el que ella ve su tarea propia. Metafísica es el título para la filosofía en sentido propio, lo que en cada caso constituye el pensamiento fundamental de la filosofía. Del predominio y de la historia de esa palabra depende la configuración espiritual del mundo de Occidente y con ello del mundo en general. «En la historia, las palabras son con frecuencia más poderosas que las cosas y los hechos» ${ }^{19}$. Metafísica es el título, entonces, para el lugar de las auténticas preguntas de la filosofía. Todas las preguntas están dirigidas por una pregunta única. El peguntar inicial del saber filosófico original tiene ya un saber de sí mismo. La filosofía pregunta por la archê. Por el principio del ente, es decir de todo lo que es. Allí el ente es visto como ente y en su totalidad. De acuerdo con esto, la pregunta de la filosofía puede plantearse de la siguiente forma ti to on, ¿qué es el ente? Encontrar respuesta a esta pregunta es la primera tarea de la filosofía. ¿Qué es el ente?: ésta es la pregunta conductora de la metafísica.

A la posición que resulta de esta pregunta conductora, ella misma no desplegada, Heidegger le llama la posición metafísica fundamental. «¿Qué es el ente?» es la pregunta conductora, pero la pregunta fundamental es más originaria, y sostiene y guía en realidad a aquélla. A partir de la pregunta conductora, Heidegger trata de llegar a la pregunta fundamental. Cuando se pregunta: ¿qué es el ente?, se alude a todo. Fuera del ente, es decir del todo, no hay nada, pero esta nada no es simplemente otro ente. ¿Qué es el ente, aquello que hace del ente un ente, la entidad del ente, la ousia del on? Preguntamos por el ser del ente. El ser del ente experimenta inmediatamente su cercanía con la nada en su pregunta. Hay siempre una región del ente que da la medida para mensurar el ente en su totalidad. Ésta conduce a una aclaración.

Heidegger, a partir de la indagación anterior, trata de ver la respuesta que da Nietzsche a la cuestión fundamental sobre la constitución del ente y su modo de ser. Ya sabemos que, con respecto al ente en su totalidad, Nietzsche da dos respuestas: «el ente en su totalidad es voluntad de poder y es eterno retorno de lo mismo». «El ente en su totalidad es voluntad de poder» significa que el ente, en cuanto tal, tiene la constitución de lo que Nietzsche llama voluntad de poder. Y «el ente en su totalidad es eterno retorno» significa, en la interpretación heideggeriana, que el ente total es, en cuanto ente, en el modo de ser del eterno retorno. La voluntad de poder responde al ente por su constitución y el eterno retorno responde al ente respecto a su modo de ser. Constitución y modo de ser se co-pertenecen.

La constitución del ente exige en cada caso un modo de ser y lo exige como su propio fundamento. Dentro de la filosofía occidental, la posición de Nietzsche sería el final de la metafísica, en la medida en que vuelve al pensar griego,

19. Ibid., p. 362 . 
lo recoge a su manera y cierra el círculo que forma la totalidad de la marcha de la pregunta en cuanto al ente en cuanto tal. Nietzsche no repite la respuesta a la pregunta inicial que al principio tenía. Con la respuesta que da Nietzsche, las posiciones esenciales del comienzo aparecen de forma transformada. Las respuestas fundamentales que se da a la pregunta por el ente al inicio son las de Parménides y Heráclito. La respuesta de Nietzsche implica para Heidegger, como ya vimos, una conjunción de las dos. El ente es, el ente deviene. Es y ser quiere decir, para lo que vendrá, consistencia y presencia, eterno presente. La respuesta de Heráclito es insuficiente en la interpretación de Nietzsche, el ente es devenir, desplegarse antitético, destruirse. Nietzsche dice que el ente es en cuanto algo fijado, algo consistente, y es un constante crearse y destruirse. El ente es ambas cosas no de un modo extrínseco, sino que el ente es fundamentalmente un constante crear, devenir, y, en cuanto crear, necesita de un hecho fijo, por una parte para superarlo y por otra, en cuanto crear, necesita de aquello que ha sido fijo. Nietzsche quiere que «imprimamos en nuestra vida la imagen de la eternidad». Llevar al ente y a nosotros, en cuanto ente, a la eternidad; imprimir al devenir el carácter de ser, que es la suprema voluntad de poder.

Esto no quiere decir suprimir y suplantar el devenir en cuanto inconsistente por el ente en cuanto consistente, sino que quiere decir configurar como ente al devenir de manera tal que se conserve como devenir y tenga existencia consistente, es decir, sea. Este convertir en ente a lo que deviene es la suprema voluntad de poder.

La transformación en ente de lo que deviene — la voluntad de poder en su figura suprema- es, en su esencia más profunda, instantaneidad, es decir, eterno retorno de lo mismo [...]. La voluntad de poder, en su esencia y por su posibilidad interna, es eterno retorno de lo mismo ${ }^{20}$.

Que todo retorna es el más extremo acercamiento del mundo del ser al mundo del devenir. Incluso, dice Heidegger, en el período de predominio de sus escritos póstumos (1884-1888), reunidos con el título de «La voluntad de poder», sigue siendo el eterno retorno el pensamiento predominante en Nietzsche. Lo que retorna eternamente como lo mismo, y de esta manera es presencia consistente, tiene la constitución de ser voluntad de poder. En su pensamiento más esencial, entonces, Nietzsche estaría fusionando las dos determinaciones fundamentales del ente que provienen del inicio de la filosofía occidental: el ente como devenir, el ente como consistencia. Lo decisivo no es que se fusionen las dos determinaciones esenciales del principio, sino cómo sucede esto. Los filósofos que ven el inicio, especialmente Hegel, lo ven a la luz de lo que es ya un decaimiento, la filosofía platónica. Nietzsche mismo designa su filosofía como un platonismo invertido. Al volver el pensamiento del inicio, el círculo se cierra. El círculo que se cierra de esta manera no libera ya ninguna posibilidad de preguntar por la pregunta conductora.

Para designar su posición metafísica fundamental, Nietzsche usó la palabra amor fati, amor a la necesidad. Amor es voluntad que quiere que lo amado sea en su esencia lo que es; es lo que eleva lo querido, en su esencia, a las posibilida-

20. Ibid., p. 375 . 
des supremas de su ser. Fatum es el estado de necesidad que, al asumir el instante, se descubre como la eternidad en plenitud del devenir del ente. El fatum trae desolación para quien se queda allí y se deja invalidar por él. Sin embargo es el mayor de los placeres para quien sabe y comprende que pertenece a él en cuanto creador, es decir, siempre en cuando decide.

\section{COMENTARIOS ACERCA DEL ETERNO RETORNO DEL NIETZSCHE DE HEIDEGGER}

El planteamiento de Heidegger, a nuestro entender, nos ayuda a comprender mejor la propuesta de él mismo que la de Nietzsche. De alguna manera, lo «sustancializa» para «colocarlo» dentro de sus propios planteos, para mostrar así su insuficiencia con respecto a la supuesta pregunta fundamental de la metafísica que aquél no estaría permitiendo desplegar. Desde nuestro punto de vista, en vez de «sustancializar», es decir, tornar metafísica la propuesta del eterno retorno, habría que «relativizarla». Habría que colocarla dentro de los parámetros, no de una manera de entender o manifestar la esencia del mundo, sino de un punto de vista (el ángulo del que hablaba Heidegger) que ayuda a fortalecer al hombre, a hacerlo mejor, y a vivir su tiempo, su único tiempo, que es precisamente el presente. Por eso, nosotros insistimos no tanto en el Nietzsche metafísico, o del fin de la metafísica, como lo hace Heidegger, sino en el Nietzsche ético, que ha encontrado en definitiva una idea que le ayuda a superar el nihilismo pasivo y a cultivar al superhombre.

Sin embargo, todo el análisis que hace Heidegger es más que interesante en algunos puntos: en la relación que establece entre voluntad de poder y eterno retorno, por ejemplo, haciendo de aquélla el fundamento de éste; también en la prevalencia que le da al instante sobre el tema de la eternidad, en relación con el eterno retorno.

Son interesantes las puntualizaciones que hace acerca del nihilismo. La idea del eterno retorno supone un estado de cosas, el nihilismo, y ayuda a superar este nihilismo pasivo trocándolo en nihilismo activo en términos de Vattimo, en voluntad de poder.

Por último, nos parece también sumamente importante la jerarquía que le da a la idea del eterno retorno como un pensamiento fundamental dentro de la filosofía Nietzscheana, aún más que la idea de la voluntad de poder (sin la cual, por supuesto, no se entendería el eterno retorno), aspecto que compartimos plenamente. La idea del eterno retorno es una de las ideas fundamentales para Nietzsche, que unifica su pensamiento, y que no puede ser entendida si no nos referimos también a las demás ideas centrales de su pensamiento (como muy bien lo explícita también Heidegger): la voluntad de poder, la idea del superhombre, el amor fati, el nihilismo, etcétera.

Con respecto al amor fati, nos parece que realmente es la clave que nos ayuda a sintetizar de alguna manera, si no la posición metafísica fundamental de Nietzsche, sí el contenido profundo de la idea del eterno retorno. Amar el destino, amar lo que es, lo necesario, elegirlo, pues nos pertenece en cuanto creadores, en la medida en que asumimos el instante como nuestro por la eternidad y, en esa misma medida, afirmamos la vida. 


\section{EL ETERNO RETORNO DESDE EL PUNTO DE VISTA ÉTICO}

Quisiéramos ahora abundar brevemente sobre nuestro punto de vista. Tenemos, como ya se ha mencionado, como primera aparición de la idea del eterno retorno en el Zaratustra, el aforismo 341 de La gaya ciencia. En esta obra inmediatamente anterior al Zaratustra aparece un aforismo que bien puede servirnos de introducción a la idea del eterno retorno en el libro posterior y que muestra que de alguna manera la idea del eterno retorno no surgió repentinamente, sino que es coherente con toda la propuesta Nietzscheana de la filosofía del amanecer $^{21}$. Vayamos entonces al aforismo 341 titulado «El peso más abrumador»y tomémoslo como una primera aparición clara y contundente de la forma que adquiere la idea del eterno retorno en Nietzsche:

El peso más abrumador: ¿¿Qué sucedería si un día, o una noche, un genio te fuese siguiendo hasta adentrarse en tu más solitaria soledad y te dijese: «Esta vida, tal y como tú la vives ahora y la has vivido, tendrás que vivirla una vez más e incontables veces más; y no habrá en ella nada nuevo, sino que todo el dolor y todo el placer, y todo pensamiento y suspiro, y todo lo indecible pequeño y grande de tu vida tiene que volver a ti, y todo en el mismo orden y secuencia, e igualmente esta araña y esta luz de la luna entre los árboles, e igualmente este instante y yo mismo. Al eterno reloj de arena de la existencia se le dará vuelta una vez y otra, iy a ti con él, polvillo de polvo»? ¿No te arrojarías al suelo y harías rechinar los dientes y maldecirías al genio que hablase así? ¿ $\mathrm{O}$ acaso has experimentado alguna vez un instante enorme en el que le respondieses: «iEres un dios y nunca he oído nada más divino!»? Si aquel pensamiento cobrase poder sobre ti, transformaría al que ahora eres y quizás te despedazaría; la pregunta «¿quieres esto una vez más, e incontables veces más?», referida a todo y a todos, igravitaría sobre tu actuar como el peso más abrumador! Pues ¿cómo podrías llegar a ver la vida, y a ti mismo, con tan buenos ojos que no deseases otra cosa que esta confirmación y ese sello últimos y eternos? ${ }^{22}$.

Es éste un hermoso texto donde aparece la idea del eterno retorno, que será una de las ideas fundamentales del pensamiento Nietzscheano, desarrollada principalmente en el último período de su obra. Si hay varios aspectos a destacar en la llamada «doctrina» (llamada así por el mismo Nietzsche), uno es el científico o "cosmológico» ${ }^{23}$ u ontológico (como lo es en la interpretación heideggeriana de Nietzsche) y otro el ético-práctico. En este aforismo se va a destacar el aspecto ético de la doctrina, su carácter existencial y éste sería para nosotros su aspecto fundamental. Lo interesante de este aforismo es que el pensamiento del retorno es tomado como algo conjetural. Dice Nietzsche: «¿Qué sucedería si...?», la forma gramatical da pie a que podamos tomar así el pensamiento del

21. Según Vattimo por ejemplo, y esto es importante destacarlo, el penúltimo libro del libro cuarto de Humano demasiado humano puede verse como antecedente del aforismo 341 de La gaya ciencia. Allí podemos ver que la idea del eterno retorno es sólo otra formulación de la aprobación incondicionada de la vida que constituye el espíritu de la filosofía del primer período; cf. Introducción a Nietzsche, cit.

22. FW $₫ 330$, las cursivas no son nuestras.

23. Es importante destacar que este aspecto no parece en ninguna obra revisada y editada durante la vida lúcida de nuestro filósofo. 
eterno retorno. Si partimos del perspectivismo Nietzscheano ${ }^{24}$, idea que podemos rastrear en toda su obra pero que se hace patente sobre todo en $\mathrm{WM}^{25}$, la verdad es una mentira (esto es, una convención, una interpretación) de alguna manera impulsada por la voluntad de poder ${ }^{26}$. Lo que tenemos no son hechos sino interpretaciones ${ }^{27}$, una serie de interpretaciones que por sí mismas no tienen más valor, ni más verdad que otras. Aunque esto no quiere decir que no puedan ser defendidas como más valiosas unas que las otras. En el fondo, los criterios de valor Nietzscheanos, son, al decir de Vattimo, «fisiológicos» (nosotros los llamaríamos más bien «vitales»). Es decir, se trata de promover los valores, entendidos como interpretaciones que redunden en la salud y nos alejen de la enfermedad, que nos den fuerza sobre la debilidad, energía activa sobre la pa$\operatorname{siva}^{28}$. Es decir, que aumenten nuestra voluntad de poder. De alguna manera, y como está claramente dicho en La voluntad de poder, el pensamiento del eterno retorno puede entenderse además como un pensamiento educativo. Nos enseña el tipo de hombre que debemos promover y formar: aquel ser humano que sea capaz de soportar el retorno, y no sólo soportarlo, sino quererlo. Y sólo puede querer el retorno de su propia vida y con ella, la del todo (pensamiento que también aparece en WM), quien le dice sí a la vida. El pensamiento afirmativo, que es propio del héroe trágico, es una constante en el pensamiento Nietzscheano. También podemos mencionarlo en este contexto como amor fati ${ }^{29}$ : amar la vida, incluyendo todo su dolor, por lo que ella es. Con la categoría de lo trágico, que aparece en El nacimiento de la tragedia (su primera obra, donde podemos encontrar lo que va a ser la sustancia de su filosofía), Nietzsche se refiere a la naturaleza de toda la realidad, que es una ${ }^{30}$. La aceptación de la vida en su unidad trágica, implica la aceptación de los contrarios ${ }^{31}$. La óptica trágica es la que nos lleva entonces al amor fati, a aceptar la vida en la plenitud de su alegría y dolor $^{32}$. Se debería impulsar en este individuo, al que podemos llamar trágico, cada instante de la existencia universal ${ }^{33}$ Vayamos al aforismo de La gaya ciencia. «Que sucedería si....»; Nietzsche está planteando una situación hipotética: que sucedería entonces si tu vida, tal y como la vives ahora y las has vivido, se repitiera ad infinitum. Y se repitiera tanto lo pequeño como lo grande, lo pueril y lo importante, la tristeza y el dolor, cada segundo. Qué pasaría si ocurriera una

24. Nietzsche afirma sobre este concepto lo siguiente: «El mundo es algo 'cognoscible', en cuanto la palabra 'conocimiento' tiene algún sentido; pero, al ser susceptible de diversas interpretaciones, no tiene un sentido fundamental, sino muchísimos sentidos. Perspectivismo» (WM $\$ 337$ ).

25. Editada ya cuando Nietzsche había perdido la razón, o sea, que fue escrita por él, pero ordenada y editada por otros. Sobre el problema de la edición de esta obra, cf. E. Fink, La filosofía de Nietzsche, Barcelona: Alianza, 1977.

26. Cf. WM $\$ \$ 399$ y 440.

27. WM $\$ 337$.

28. «Enseño no contra lo que debilita, contra todo lo que agota. Enseño sí hacia todo lo que fortalece, acumula fuerzas, justifica el sentimiento de la fuerza» (WM $\$ 66$, las cursivas no son nuestras).

29. «El no querer que nada sea distinto, ni el pasado ni el futuro ni por toda la eternidad. No sólo soportar lo necesario, y aún menos disimularlo - todo idealismo es mendicidad frente a lo necesario-, sino amarlo» (EH, Madrid: Alianza, 1997, p. 61).

30. Aquí se hace más patente el Nietzsche ontológico.

31. Cf. P. Rivero Weber, Nietzsche, verdad e ilusión, México: Gerardo Villegas. ¿̇año?

32. WM $\$ 39$.

33. Cf. WM $\$ 69$. 
eterna repetición de lo mismo. Y no sólo la persona misma sino la persona con el «todo», con el contexto del que formo parte. Si se diera esto, ¿qqué sucedería? $\underline{34}$ : ¿sería éste el pensamiento más espantoso que podríamos pensar?, ¿sería una especie de infierno ${ }^{35}$ (al que parece aludir Nietzsche con la idea del «rechinar los dientes» y del «demonio» que así habla)?, ċo acaso un paraíso, donde se es un Dios y nunca se escuchó algo tan divino? Nietzsche apunta a la fuerza pragmática, ético-transformadora del pensamiento del eterno retorno, que mide las fuerzas. Como tal, no como realidad, sino como pensamiento, puede efectuar una transformación. Y se puede enunciar como una especie de fórmula práctica a lo Nietzsche que diría: «Vive tu vida tal y como si se fuera a repetir» ${ }^{36}$; ante cada hecho y o acción de tu vida te preguntarías: «¿Quieres esto una vez e innumerables veces más?». Eso implicaría que en cada acto habría una voluntad de afirmación de la vida, tal y como se vive, elegida por ahora y por siempre. Pero también implicaría, en el caso de que se tomara esta fórmula como posibilidad, muy exigente desde el punto de vista ético-práctico, que nadie querría vivir su vida en forma insustancial, como algo pasajero, como algo que no exige, en definitiva, toda la decisión y la participación del sujeto. Éste trabajará en torno, no a un más allá incierto, o a una recompensa futura, sino frente a un más acá, que exige todo el compromiso de la voluntad, dado que ésta debe actuar como si todo acto o pensamiento se fuera a repetir infinitamente. Ese instante en que me decido, y elijo mis actos, es decisivo para toda la eternidad. Sólo el superhombre, el hombre que está más allá del bien y del mal, puede decidirse por este instante. $\mathrm{Al}$ conocer la significación eterna de este instante que vivo, puedo entonces vivir de manera más intensa y decidida. No se trata de una eternidad transmundana (como propone la moral judeocristiana), sino del mundo mismo en el que me decido. Aquí se justifica el mundo que soy yo mismo con mi decisión de vivir este mismo instante por la eternidad. Este pensamiento, para Nietzsche, nos hace poderosos, nos hace activos.

\section{FUERZAS ACTIVAS Y FUERZAS REACTIVAS}

Lo anterior se relaciona con una idea interesante, dentro de la interpretación deleuziana de Nietzsche, que nos gustaría destacar para concluir este trabajo. Podríamos decir que la doctrina del eterno retorno, lejos de contradecirse con la idea de la voluntad de poder, constituye su metáfora. Para Gilles Deleuze ${ }^{37}$ el eterno retorno es la síntesis cuyo principio es la voluntad de poder. Lo que Nietzsche llama alto, noble y señor, tal y como aparece por ejemplo en La genealogía de la moral, es en la interpretación que Deleuze hace de Nietzsche y

34. Se puede decir que la filosofía de Nietzsche es experimental, experimenta y nos invita a experimentar con distintos sentidos posibles.

35. El eterno retorno puede ser el pensamiento más espantoso que se puede pensar, desde la perspectiva del nihilista pasivo: "la existencia tal como es, sin sentido y sin finalidad, pero inevitablemente retornando sobre sí, sin llegar a un final en la nada: 'el eterno retorno'» (WM $\$ 68$ ).

36. Lamentablemente no podemos detenernos ahora en este punto, pero se puede ver nuestro artículo «Nietzsche versus Kant»: Revista Actio 5 (septiembre de 2004) <http://www.fhuce.edu. uy/public/actio/Textos/5/AndreaDiaz.pdf $>$.

37. G. Deleuze, Nietzsche y la filosofía, Barcelona: Anagrama, 1971. 
en La genealogía misma la fuerza activa. Y la fuerza activa afirma su diferencia. Por el contrario, las fuerzas reactivas actúan separando a la fuerza activa de lo que ésta puede, terminan negando y no afirmando. Cuando las fuerzas activas devienen reactivas, triunfa el nihilismo ${ }^{38}$, otra de las ideas centrales en el pensamiento Nietzscheano ${ }^{39}$. El devenir activo es afirmador y afirmativo, y el reactivo negador y nihilista. Un devenir activo sólo puede ser pensado como producto de una selección, que es la que se opera en el pensamiento del eterno retorno, y que implica voluntad de poder, es decir, poder activo, decisivo. Esta selección opera, para Deleuze, como regla práctica de la voluntad. Como sigue diciendo en el aforismo 341 de La gaya ciencia: «Frente a todo y en cada caso, la pregunta ¿quieres esto una vez e innumerables veces más?, irecaería sobre tu acción como la mayor gravedad! $»^{40}$. Hay que liberarse de alguna forma de lo que se quiere una sola vez, hay que entrar en un querer total, el querer por la eternidad: ése sí es un querer radical, profundo. El nihilismo pasivo ${ }^{41}$ es el principio de conservación de una vida débil, disminuida, reactiva, la depreciación de la vida, la negación de la vida. Con el eterno retorno el nihilismo se vuelve completo (en tanto nihilismo activo), porque hace de la negación una negación de las propias fuerzas reactivas $^{42}$. El nihilismo en el eterno retorno es la destrucción de la debilidad ${ }^{43}$. Los espíritus fuertes destruyen lo que hay de reactivo en ellos sometiéndolo a la prueba del eterno retorno y sometiéndose ellos mismos a esa prueba. Negación de las propias fuerzas reactivas, como la única forma en que las fuerzas activas se vean trasmutadas. Se trata de un devenir activo como afirmador, y es el eterno retorno quien produce este devenir activo. El hombre pequeño, reactivo, no regresará. El nihilismo vencido por él mismo, mediante el eterno retorno. Según Deleuze, la relación propia de la voluntad de poder con el eterno retorno exige la posibilidad de una nueva forma de sentir, de pensar, y, sobre todo, una nueva forma de ser (el superhombre). Para el autor, la «inversión de valores» significa

38. «Un nihilista es el hombre que piensa que el mundo, tal como es, no tiene razón de ser, y que el mundo, tal como debería ser, no existe. Por tanto, el hecho de existir (obrar, sufrir, querer, sentir) carece de sentido: la actitud del 'en vano' es la actitud del nihilista: en cuanto actitud, es, además, una inconsciencia del mismo» (WM $\$ 400$ ).

39. Para profundizar más en el nihilismo ver todo el libro primero de La voluntad de poder, titulado «El nihilismo europeo» (WM $\mathbb{S}$ 33-119). En una primera parte de este ensayo Nietzsche resume el nihilismo como la consecuencia» de la forma en que se han interpretado hasta ahora todos los valores de la existencia» (WM $\$ 35$ ). Lo que llama el «nihilismo radical» sería precisamente «el convencimiento de la insostenibilidad de la existencia» (WM $\$ 35$ ). Hay todo un proceso por etapas hasta llegar a un nihilismo radical. El mismo cristianismo forma parte de ese proceso nihilista como veremos a lo largo del libro. Adviértase que la parte IV se dedica específicamente al nihilismo y su relación con la idea del eterno retorno: «... la existencia tal como es, sin sentido y sin finalidad, pero inevitablemente retornando sobre sí, sin llegar a una finalidad en la nada 'El eterno retorno'. iÉsta es la forma más extrema de nihilismo!: ila nada ('el absurdo') eterna!» (WM $\$ \mathbb{S} 68-69$ ).

40. Ibid.

41. El nihilismo en Nietzsche tiene un doble sentido: «A) El nihilismo como signo del creciente poder del espíritu: nihilismo activo. B) El nihilismo como decadencia y retroceso del poder del espíritu: nihilismo pasivo» (WM $\$ 45$ ).

42. Ibid., 101. ¿ página o parágrafo?

43. Hay que ser cuidadosos a la hora de leer La genealogía para evitar en todo lo posible relacionar alguno de sus pasajes, descolgados de los demás, con ideas de corte fascista, que nada tienen que ver con la filosofía Nietzscheana. Cf. a propósito de este tema el dossier sobre «Nietzsche y el nacionalsocialismo. Historia de una apropiación»: Perspectivas Nietzscheanas (1993). 
activo en vez de reactivo, $\mathrm{y}$ «transmutación de valores» significa afirmación en lugar de negación. No se puede afirmar el ser del devenir, sin afirmar un devenir activo. Querer libera, ésa es la verdadera doctrina de la voluntad y de la libertad. Querer es crear nuevos valores. La voluntad es, en este sentido, «alegre» para Nietzsche.

¿Por qué tiene que valer más la afirmación que la negación? La solución sólo nos vendrá dada con la prueba del eterno retorno: vale más, y vale absolutamente, lo que vuelve, lo que soporta volver, lo que quiere volver. El eterno retorno trasmuta lo negativo: hace de lo pesado algo ligero, hace pesar lo negativo al lado de la afirmación, hace de la negación un poder de afirmar ${ }^{44}$.

En lugar de un conocimiento que se opone a la vida, se establece un pensamiento que afirmaría la vida. La vida sería la fuerza activa del pensamiento, pero el pensamiento sería el poder afirmativo de la vida. Pensar significaría descubrir e inventar nuevas posibilidades de vida. La vida haciendo del pensamiento algo activo, el pensamiento haciendo de la vida algo afirmativo. La mayor gravedad, como se titula este aforismo de La gaya ciencia, es precisamente este pensamiento que se presenta como síntesis práctica, y que nos impele a actuar con la mayor radicalidad y decisión, pues el producto de esta decisión se repetirá innumerables veces, regresará eternamente.

44. En La genealogía de la moral podemos ver claramente la descripción de Nietzsche del tipo reactivo, como el tipo sacerdotal, el tipo ascético. 